\title{
PREFERENSI RELUNG PAKAN BADAK JAWA DAN BANTENG
}

\section{(Dietary Niche Preference of Javan Rhinoceros and Banteng)}

\author{
ROIS MAHMUD ${ }^{1 *)}$, AGUS PRIYONO KARTONO ${ }^{2)}$ DAN LILIK BUDI PRASETYO ${ }^{2)}$ \\ 1) Program Studi Konservasi Biodiversitas Tropika, Sekolah Pasca Sarjana Institut Pertanian Bogor, Kampus \\ Darmaga, Bogor, Indonesia 16680 \\ 2) Departemen Konservasi Sumberdaya Hutan \& Ekowisata, Fakultas Kehutanan Institut Pertanian Bogor, Kampus \\ Darmaga, Bogor, Indonesia 16680
}

*Email: rois_kvt16@apps.ipb.ac.id

Diterima 21 November 2019 / Disetujui 13 April 2020

\begin{abstract}
The Javan Rhinoceros population living in Ujung Kulon National Park is the last population of this species remains globally. Some studies have concluded that there has been competition between the Javan Rhinoceros and the banteng based on the number of overlapping ecological niches. However, recent research on the status of interspecific interactions of both species indicates an indication of the niches partitioning of space and time with no evidence of aggressive behavior. This research aims to conclude the feeding competition between the Javan rhino and the banteng in Ujung Kulon National Park. The research was conducted by observing 8 vegetation analysis plots in Ujung Kulon Peninsula representing the concentration area of the Javan rhinos and the banteng. The inventory of Javan rhinoceros and banteng feed compare the availability of all types of vegetation at the observation sites are conducted to assess the feed preference of both species. Preference analysis is done by calculating the Neu index for each observation plot and comparing the value of the standardized preference of the entire observation plot. The observation identified 65 types of vegetation that were eaten by both species where there were 15 types of vegetation overlapping. The kind that the Javan rhinoceros most preferred are the types that are not preferred by the banteng and vice versa. The findings suggest that there is no exploitative competition and there is an indication of the feeding niche partitioning between the Javan rhino and the banteng.
\end{abstract}

Keywords: banteng, feed preference, javan rhinoceros, niche partition, Ujung Kulon National Park

\section{ABSTRAK}

Populasi badak jawa yang hidup di Taman Nasional Ujung Kulon merupakan populasi terakhir spesies tersebut di dunia. Beberapa penelitian menyimpulkan bahwa telah terjadi persaingan antara badak jawa dan banteng berdasarkan banyaknya tumpang tindih relung ekologisnya. Namun penelitian terakhir mengenai status interaksi interspesifik dari kedua spesies menunjukkan adanya indikasi pembagian relung ruang dan waktu dengan tanpa adanya indikasi perilaku agresif. Penelitian ini bertujuan untuk menyimpulkan kembali persaingan relung pakan antara badak jawa dan banteng di Taman Nasional Ujung Kulon. Penelitian dilakukan dengan pengamatan delapan plot analisa vegetasi di semenanjung Ujung Kulon yang mewakili area konsetrasi badak jawa dan banteng. Inventarisasi bekas pakan badak jawa dan banteng beserta ketersediaan seluruh jenis tumbuhan pada lokasi pengamatan dilakukan untuk menilai preferensi pakan dari kedua spesies. Analisa preferensi dilakukan dengan perhitungan indeks Neu untuk setiap plot pengamatan dan membandingkan nilai preferensi yang sudah distandarisasi dari seluruh plot pengamatan. Hasil pengamatan mendapatkan 65 jenis tumbuhan yang dimakan kedua spesies dengan 15 jenis tumbuhan yang tumpang tindih. Jenis yang disukai badak jawa merupakan jenis yang tidak disukai oleh banteng dan sebaliknya. Temuan tersebut menunjukkan bahwa tidak terjadi persaingan baik yang bersifat exploitative dan terdapat indikasi terjadinya pembagian relung pakan antara badak jawa dan banteng.

Kata kunci: badakjawa, banteng, pembagian relung, preferensi pakan, Taman Nasional Ujung Kulon

\section{PENDAHULUAN}

Taman Nasional Ujung Kulon (TNUK) merupakan kawasan konservasi yang dihuni oleh populasi terakhir badak jawa (Rhinoceros sondaicus, Desmarest 1822) yang tersisa di dunia saat ini. Ukuran populasinya juga sangat kecil yaitu hanya tersisa 69 individu saja (KLHK 2019) sehingga International Union for Conservation Nature (IUCN) mengkategorikannya sebagai spesies Critically Endangered atau sangat terancam punah (Van Strien et al. 2008). TNUK juga merupakan habitat dari jenis satwa langka lainnya yaitu banteng (Bos javanicus, d'Alton 1823). Banteng termasuk dalam kategori Endangered atau terancam punah dalam redlist IUCN
(Timmins et al. 2008). Kedua spesies hidup secara simpatrik di semenanjung TNUK. Status dari kedua spesies yang sama-sama dalam kategori terancam tersebut membuat program konservasi yang tepat diperlukan untuk melestarikannya.

Segala kesulitan dalam upaya pelestarian dari kedua spesies ternyata masih harus bertambah dengan banyaknya temuan petunjuk bahwa kedua spesies langka ini mempunyai potensi yang tinggi untuk saling merugikan satu sama lain dalam hal perebutan sumberdaya yang sama. Alikodra (1983) menyimpulkan bahwa telah terjadi perubahan perilaku dari banteng yang seharusnya adalah jenis satwa grazer menjadi lebih bersifat browser. Perubahan perilaku tersebut membuat 
tumpang tindih relung pakan dari kedua spesies menjadi semakin besar dan berpotensi terjadi perebutan sumberdaya pakan. Kesimpulan tersebut juga didukung oleh temuan dari peneliti-peneliti selanjutnya yang menemukan banyak tumpang tindih relung sumberdaya antara badak jawa dan banteng. Ditemukan 75 jenis tumbuhan pakan yang tumpang tindih dimakan oleh kedua spesies dari 132 jenis pakan kedua spesies yang ditemukan $(56,8 \%)$ dan juga bahwa banteng ditemukan pada area rumpang yang merupakan area pakan bagi badak jawa (Muntasib dan Masyúd 2000). Badak jawa dan banteng juga ditemukan menggunakan sumber air yang sama serta menggunakan beberapa jenis sumberdaya yang sama sehingga bisa dikategorikan bahwa telah terjadi persaingan tidak langsung atau exploitative competition (Suhono dan Muntasib 2001). Senada dengan penelitian-penelitian tersebut, Yayasan Mintra Rhino juga menemukan adanya sejumlah tumpang tindih relung pakan antara badak jawa dan banteng sehingga semakin menguatkan kesimpulan persaingan tersebut (YMR 2002). Para peneliti menyarankan untuk mulai melakukan antisipasi agar indikasi persaingan tersebut tidak semakin buruk sehingga akan merugikan kedua spesies. Saran tersebut adalah melakukan pengelolaan padang rumput agar konsentrasi banteng bisa berkurang pada habitat badak jawa (Muntasib dan Masyúd 2000).

Berbagai pengertian mengenai persaingan yang dicetuskan oleh para ahliekologi di antaranya Birch (1957), Reynoldson and Bellamy 1971, Wilson 1975 dan lain sebagainya dalam Wiens (1992) selalu menempatkan beberapa aspek kunci sebuah interaksi bisa dikatakan persaingan atau tidak (Wiens 1992). Beberapa aspek kunci tersebut adalah sumberdaya terbatas sehingga salah satu spesies atau individu tidak mendapatkan bagian atau tertutup aksesnya untuk mendapatkan sumberdaya tersebut karena pihak yang lain (Wiens 1992). Berdasarkan pengertian tersebut, maka persaingan membutuhkan pembuktian dari keterbatasan sumberdaya dan atau tidak dapatnya salah satu pihak bagian dari sumberdaya karena pihak yang lain untuk menentukan kompetisi telah terjadi. Terjadi exploitative competition jika sumberdaya bebas diakses oleh keduanya namun habis oleh pihak yang pertama mengaksesnya dan terjadi interference competition ketika kehadiran salah satu pihak menghalangi akses pihak lain kepada sumberdaya yang biasanya karena perilaku agresifnya (Wiens 1992). Bukti yang diajukan oleh peneliti-peneliti untuk menyimpulkan bahwa telah terjadi persaingan antara badak jawa dan banteng di Taman Nasional Ujung Kulon belum dapat membuktikan keterbatasan sumberdaya maupun terhalangnya akses sumberdaya oleh salah satu pihak antara badak jawa dan banteng.

Mahmud et al. (2016) mencoba untuk melakukan pembaharuan terhadap informasi status interaksi interspesifik dari badak jawa dan banteng namun tidak menemukan indikasi persaingan tersebut. Metode yang digunakan adalah metode occupancy (MacKenzi et al.
2006) yang dikembangkan lebih lanjut oleh Richmon et al. (2010) menjadi conditional two-species occupancy model. Model ini digunakan untuk mendeteksi kecenderungan menghindar dari spesies subordinat dari spesies saingannya yang lebih dominan ketika ageresifitas akibat persaingan relung ekologis itu terjadi. Metode ini dirancang untuk memperkirakan kemungkinan tertutupnya akses salah satu pihak karena kehadiran pihak lain yang merupakan salah satu aspek yang harus dibuktikan untuk menyimpulkan sebuah persaingan telah terjadi.

Penelitian ini bertujuan untuk membuktikan apakah persaingan telah terjadi antara badak jawa dan banteng pada relung pakan. Penelitian dilakukan dengan menganalisa preferensi jenis pakan dari kedua spesies dengan menggunakan perhitungan indeks Neu et al. (1974). Kesimpulan dari analisa ini setidaknya akan memberikan gambaran apakah sumberdaya sudah cukup terbatas ataukah tidak bagi kedua spesies dan apakah terjadi exploitative competition antara kedua spesies. Analisa relung pakan kedua spesies dilakukan pada tingkat preferensi untuk memastikan bahwa kesimpulan persaingan tidak rancu dengan pembagian relung atau niche partitioning sebagai indikator koeksistensi (Albrecht dan Gotelli 2001).

Pembagian relung sendiri bisa merupakan sebuah fenomena permanen maupun temporal seperti yang terjadi pada badak india dan gajah asia di Nepal yang melakukan pembagian relung lebih ketika musim kering (Pradhan et al. 2008). Oleh karena itu penelitian ini hanya ingin menunjukkan indikasi bahwa terdapat kemungkinan lain dari kesimpulan penelitian-penelitian sebelumnya yang perlu didalami lebih lanjut.

\section{METODE PENELITIAN}

Survei lapangan dilakukan pada bulan November dan Desember tahun 2017 di semenanjung TNUK mengikuti jalur kegiatan dari tim monitoring badak jawa Balai TNUK. Dua jalur survei dipilih yaitu jalur tim 4 monitoring badak jawa antara area Cidaon sampai dengan Citadahan dan jalur tim 2 monitoring badak jawa antara area Nyawaan sampai dengan Cigenter wilayah semenanjung Ujung Kulon. Jalur tim 4 dipilih sebagai representasi wilayah konsenterasi terbesar badak jawa dan banteng di semenanjung TNUK sedangkan jalur tim 3 dipilih sebagai representasi area konsenterasi banteng dan bukan untuk badak jawa. Karakteristik lokasi plot pengamatan disajikan pada Tabel 1 .

Delapan plot pengematan ini masih berada pada bagian barat semenanjung TNUK sehingga untuk mendapatkan gambaran lengkap kondisi seluruh semenanjung direkomendasikan untuk juga melakukan observasi pada bagian timur semenanjung TNUK pada penelitian-penelitian selanjutnya. Pemilihan lokasi pengamatan dilakukan berdasarkan rekomendasi dari tim Rhino Monitorinng Unit (RMU). Lokasi-lokasi pengematan merupakan lokasi-lokasi yang mereka 
ketahui sebagai area makan bagi badak jawa dan banteng plot pengamatan disajikan pada Gambar 1 1. pada tipe dan kondisi habitat yang berbeda. Peta lokasi Tabel 1 Karakteristik lokasi plot analisis vegetasi

\begin{tabular}{llcl}
\hline Plot & Tipe Habitat & Ketinggian $(\mathrm{mdpl})$ & Nama blok \\
\hline 1 & Hutan pantai & 0 & Cidaon \\
2 & Hutan sekunder & 10 & Cidaon \\
3 & Hutan primer & 13 & Cidaon \\
4 & Rumpang & 38 & Cijengkol \\
5 & Rumpang & 4 & Cibunar \\
6 & Rumpang & 3 & Cibunar \\
7 & Hutan sekunder & 4 & Nyawaan \\
8 & Rumpang & 19 & Citengah \\
\hline
\end{tabular}

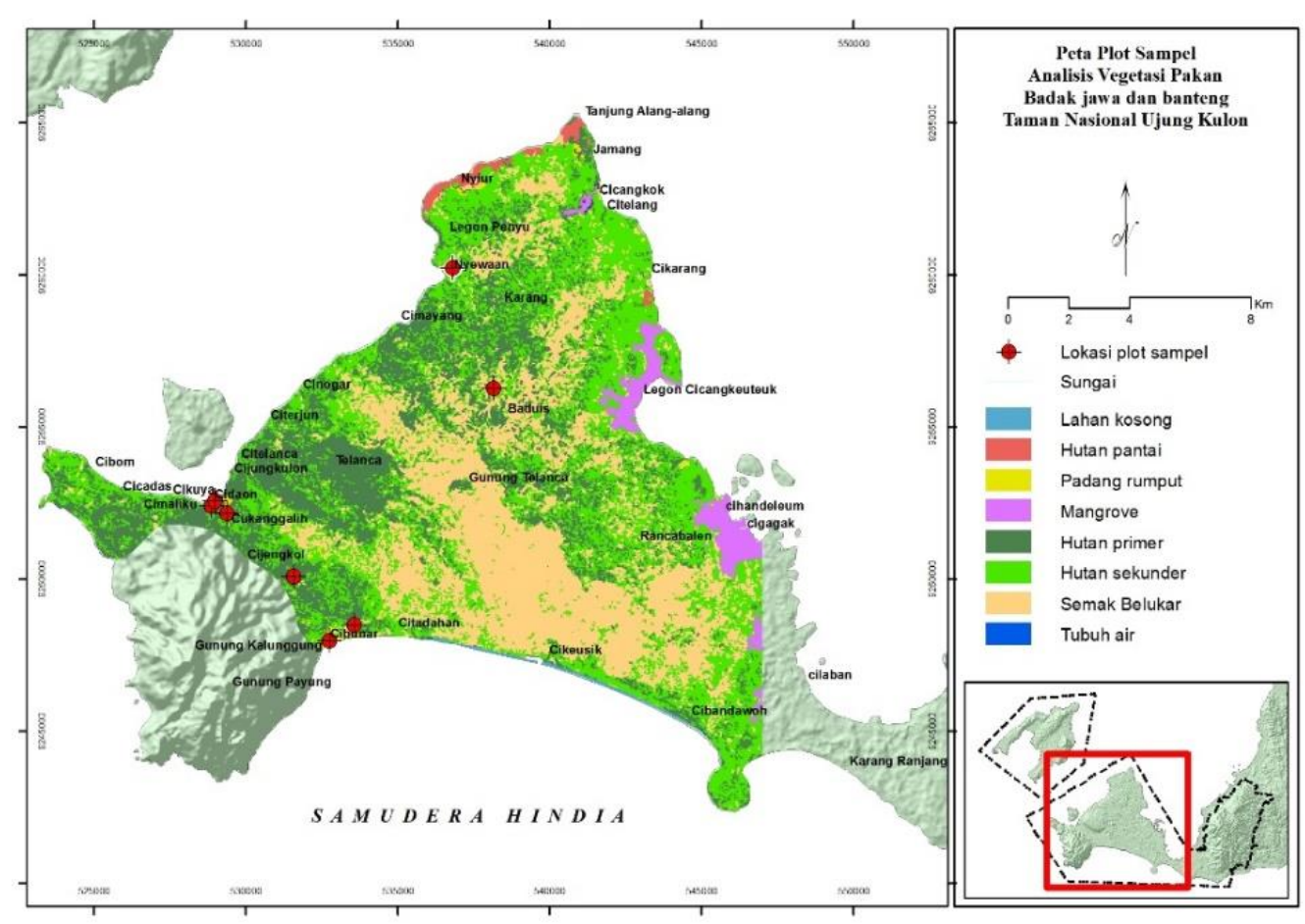

Gambar 1 Peta titik plot sampel analisis vegetasi pakan badak jawa dan banteng

Metode survei dilakukan dengan menginventarisasi jenis tumbuhan dan menghitung temuan bekas pakan badak jawa dan banteng pada plot pengamatan. Ukuran plot yang digunakan adalah $5 \times 40$ meter mengikuti Gillison et al. (1996). Penentuan plot dilakukan dengan memilih area-area dengan tanda bekas makan cukup intensif oleh badak jawa dan banteng pada tipe habitat yang berbeda. Bentuk plot analisis vegetasi mengikuti jalur pergerakan dari badak jawa dan banteng pada area tersebut karena perilaku makan badak jawa dan banteng pada area hutan adalah makan sambil berjalan mengikuti jalur. Delapan lokasi plot dilakukan inventarisasi tumbuhan dan bekas pakan badak jawa dan banteng dalam penelitian ini.

Metode analisa yang digunakan untuk menghitung nilai preferensi pakan dalam penelitian ini menggunakan perhitungan indeks Neu et al. (1974):

$$
W_{i}=\frac{u_{i}}{p_{i}}=\frac{n_{i} / \sum n_{i}}{a_{i} / \sum a_{i}}, \quad b_{i}=\frac{W_{i}}{\sum W_{i}}
$$

Keterangan:

$u_{I} \quad=$ proporsi jenis pakan ke-i yang dimakan dibandingkan dengan jumlah semua jenis yang dimakan dalam plot

$p_{i} \quad=$ proporsi jumlah jenis pakan ke-i dibandingkan dengan jumlah keseluruhan jenis pakan

$a_{i} \quad=$ ketersediaan pakan jenis ke-i

$n_{i} \quad=$ frekuensi pakan jenis ke-i yang dimakan

$w_{i}=$ indeks preferensi terhadap jenis pakan ke- $\mathrm{i}$

$b_{i} \quad=$ indeks preferensi jenis pakan ke-i yang distandarkan

Jenis pakan yang disukai diurutkan berdasarkan bi, yakni jenis pakan disukai jika $b_{i} \geq 1,00$. 
Nilai indeks Neu yang sudah distandarkan dihitung pada tiap plot pengamatan karena mempertimbagkan kemungkinan perbedaan keanekaragaman pada tiap plot tersebut dan dilakukan perhitungan rata-rata untuk dapat dibandingkan antar plot pada jenis-jenis yang didapatkan pada lebih dari satu plot pengamatan. Perhitungan dilakukan dengan menggunakan software Microsoft Excel. Beberapa informasi lain diekstrak menggunakan software $\mathrm{R}$ dengan package 'vegan' pada plot pengamatan. Beberapa informasi tersebut adalah nilai indeks biodiversitas Shannon-Wiener dan nilai indeks kekayaan jenis Chao (O'hara 2005).

Bekas pakan badak jawa dan banteng dapat dibedakan di lapangan dengan cukup mudah, menurut Ihom sebagai salah satu anggota RMU TNUK. Badak jawa dan banteng mempunyai kecenderungan memakan bagian yang berbeda dari tumbuhan. Badak jawa cenderung memakan pucuk daun sampai dengan rantingnya karena karakter morfologi mulut badak jawa yang mempunyai gigi pemotong. Cara makan badak jawa adalah dengan menarik ranting daun dan memotongnya, kemudian semua bagian yang terpotong tersebut akan dimakannya (Gambar 2). Sedangkan banteng hanya melakukan ragutan pada daun sampai dengan pucuk daun sehingga bekas pakan biasanya terdapat potongan daun dan pucuk daun.

Analisa nilai biodiversitas dan kekayaan jenis juga dilakukan pada tiap plot untuk mendapatkan gambaran umum kondisi lokasi tersebut. Analisa dilakukan dengan menggunakan software $R$ statistic dengan package vegan dalam menghitung nilai indeks biodiversitas Shannon-
Wiener dan nilai kekayaan jenis Chao. Nilai biodiversitas Shannon-Wiener secara umum dapat dikategorikan menjadi 3 kelas yaitu: nilai kurang dari $1(<1)$ berarti keanekargaman rendah, penyebaran jumlah individu tiap jenis rendah dan kestabilan komunitas rendah; nilai 1-3 berarti kenekaragaman sedang, penyebaran jumlah individu tiap jenis sedang dan kestabilan komunitas sedang; dan nilai lebih dari 3 (>3) berarti keanekaragaman tinggi, penyebaran jumlah individu tiap jenis tinggi dan kestabilan komunitas tinggi

\section{HASIL DAN PEMBAHASAN}

Pakan merupakan kebutuhan utama bagi keberlangsungan hidup makhluk hidup sehingga ketersediaan pakan merupakan salah satu faktor penentu keberadaan satwa dalam habitat tertentu (Alikodra 2002). Oleh karena itu penting untuk memahami relung pakan dari banyak spesies yang hidup bersama pada suatu habitat sebagai bahan rencana pengelolaan sumberdaya alam terutama satwaliar dalam kawasan konservasi. Delapan plot sampel pada lokasi-lokasi dimana badak jawa dan banteng memanfaatkan area tersebut sebagai area makan diinventarisasi tumbuhan dan bekas pakannya untuk mendeteksi tumpang tindih pakan antara kedua spesies. Delapan lokasi sampel sebenarnya masih terlalu sedikit untuk mewakili kondisi di keseluruhan semenanjung Ujung Kulon sehingga pada penelitian mendatang direkomendasikan untuk menggunakan desain sampling yang lebih baik.

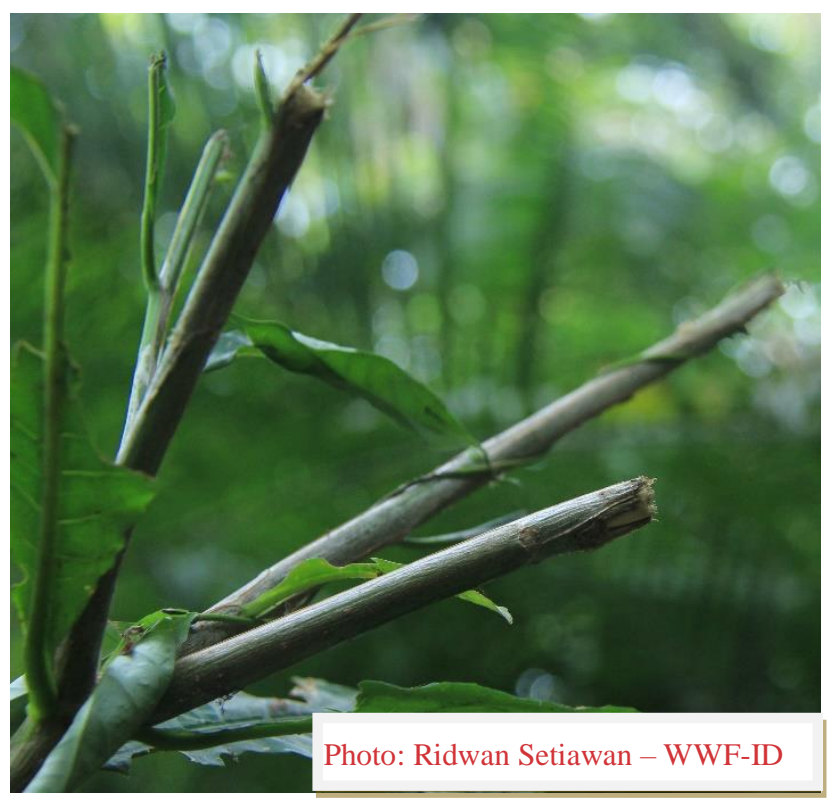

Keterangan:

Contoh bekas potongan badak jawa. Badak jawa akan memakan semua bagian mulai dari ranting yang dipotong sampai dengan pucuk daunnya.

Gambar 2 Bekas pakan badak jawa 
Pengamatan yang dilakukan pada delapan plot pengamatan berhasil mengidentifikasi 126 jenis vegetasi. 36 jenis di antaranya dimakan oleh badak jawa dan 44 jenis di antaranya dimakan oleh banteng. Tumpang tindih jenis tumbuhan pakan dari badak jawa dan banteng pada delapan plot pengamatan adalah 15 jenis. Nilai keanekaragaman indeks Shannon-Wiener (H') tumbuhan pada delapan plot pengamatan termasuk dalam kategori rendah dan sedang. Jumlah jenis tumbuhan teramati di dalam tiap plot berjumlah antara 38 jenis sampai dengan 65 jenis. Plot pengamantan pertama tidak ditemukan bekas pakan dari banteng sedangkan plot pengamatan ke 7 tidak ditemukan bekas pakan dari badak jawa. Plot pengamatan ke 7 saat ini teridentifikasi sebagai bukan wilayah jelajah badak jawa setelah temuan kematian badak jawa di wilayah tersebut pada tahun 2010 namun merupakan area yang cukup intensif digunakan oleh banteng. Gambaran umum lokasi plot sampel dapat dilihat pada Tabel 2. Temuan 10 jenis tumbuhan dengan nilai tertinggi bagi badak jawa dan banteng pada penelitian kali ini agak berbeda dengan hasil dari penelitian YMR (2002) yaitu tidak ditemukannya tumpang tindih jenis tumbuhan pakan dengan palatabilitas tertinggi pada penelitian kali ini. YMR (2002) menemukan adanya tumpang tindih pada 10 jenis tumbuhan dengan palatabilitas tertinggi namun nilai palatabilitas tertinggi dari kedua spesies bisa dikatakan sangat rendah yaitu 0,226 bagi banteng dan 0,118 untuk badak jawa. Hal ini mengindikasikan bahwa baik badak jawa atau banteng merupakan satwa yang generalis dalam pemilihan makanan atau kelimpahan jenis yang disukai masih sangat tinggi sehingga sangat kecil kemungkinan terjadi perebutan antara keduanya.
Perhitungan nilai preferensi pakan badak jawa dan banteng dilakukan untuk setiap plot dan karena nilai yang dihasilkan sudah standar maka hasil nilainya bisa diperbandingkan antar plot. Nilai kecenderungan pemilihan jenis tertentu berdasarkan nilai perhitungan indeks Neu menunjukkan bahwa badak jawa dan banteng mempunyai kecenderungan pemilihan jenis pakan (preferensi) yang berbeda. Tidak ada tumpang tindih jenis dari 10 jenis tumbuhan yang paling disukai oleh badak jawa dan banteng. Nilai preferensi tinggi dalam hal ini mempunyai dua kemungkinan kesimpulan yaitu spesies tersebut memakan dalam jumlah yang banyak mendekati jumlah ketersediaan yang cukup banyak juga atau ketersediaan yang sangat sedikit namun satwa memilih untuk memakannya. Oleh karena itu bisa terjadi perbedaan jenis dengan nilai tertinggi pada tiap plot dibandingkan dengan jenis dengan nilai tertinggi dari keseluruhan plot karena nilai dari keseluruhan plot adalah rata-rata nilai dari delapan plot tersebut.

Hasil perhitungan nilai preferensi untuk semua jenis tumbuhan yang tercatat dimakan oleh badak jawa dan banteng juga menunjukkan adanya pengelompokan (clustering) yang berbeda seperti tergambar pada Gambar 3. Tumpang tindih jenis tumbuhan pakan antara badak jawa dan banteng pada delapan plot pengamatan dari seluruh tumbuhan yang dimakan kedua spesies sangat sedikit. Hal tersebut menunjukkan bahwa jenisjenis tumbuhan yang disukai oleh badak jawa bukan merupakan jenis-jenis tumbuhan yang disukai oleh banteng dan sebaliknya. Beberapa jenis tumbuhan yang dimakan oleh badak jawa dan banteng mempunyai nilai preferensi yang kecil yang menunjukkan bahwa jenis tumbuhan tersebut cukup melimpah dan bukan merupakan pilihan utama dari kedua spesies.

Tabel 2 Tabel ringkasan temuan hasil analisa vegetasi pada tiap plot pengamatan.

\begin{tabular}{|c|c|c|c|c|c|c|c|}
\hline Plot & $\mathrm{H}^{\prime}$ & Jenis & Chao & $\begin{array}{l}\text { Bdk } \\
\text { Max }\end{array}$ & $\begin{array}{l}\text { Btg } \\
\text { Max }\end{array}$ & Vegbdk & Vegbtg \\
\hline 1 & 1,926 & 38 & 43 & 0,679 & & $\begin{array}{l}\text { Waru lot (Thespesia } \\
\text { populnes) }\end{array}$ & 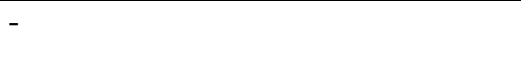 \\
\hline 2 & 2,195 & 52 & 64 & 0,727 & 0,344 & Kopo (Eugenia subglauca) & Kokopian (Memecylon edule) \\
\hline 3 & 2,106 & 39 & 69 & 0,464 & 0,237 & Kawao (Derris thyorsifolia) & Kibarela (Erioglassum rubiginosum) \\
\hline 4 & 2,389 & 56 & 79 & 0,233 & 0,287 & Huni (Antidesma bunius) & Bangban (Donax cannaeformis) \\
\hline 5 & 2,012 & 46 & 57 & 0,932 & 0,310 & $\begin{array}{l}\text { Kuku Heulang (Uncaria } \\
\text { gambir) }\end{array}$ & paku - Pakuan (Tetrania sp.) \\
\hline 6 & 2,145 & 43 & 48 & 0,307 & 0,257 & $\begin{array}{l}\text { Kuku Heulang (Uncaria } \\
\text { gambir), Tuahorong (Derris } \\
\text { heterophylla) }\end{array}$ & $\begin{array}{l}\text { Rotan Seel (Daemonorops } \\
\text { melanochaetes) }\end{array}$ \\
\hline 7 & 1,872 & 38 & 47 & & 0,248 & - & $\begin{array}{l}\text { Areuy Kibarela (Erioglassum } \\
\text { rubiginosum), Pacing (Costus } \\
\text { specistus) }\end{array}$ \\
\hline 8 & 1,924 & 65 & 80 & 0,191 & 0,307 & $\begin{array}{l}\text { Kacembang (Lecananthus } \\
\text { erubescens) }\end{array}$ & Oar (Flagellaria indica) \\
\hline
\end{tabular}

Keterangan: H'adalah nilai indeks biodiversitas Shannon-Wiener, Jenis adalah jumlah jenis tumbuhan yang ditemukan, Chao adalah nilai indeks kekayaan jenis Chao, Bdk Max dan Btg Max adalah nilai maksimal indeks preferensi Neu untuk badak dan banteng, Vegbdk dan Vegbtg adalah jenis tumbuhan yang mempunyai nilai indeks preferennsi Neu untuk badak jawa dan banteng 
Tabel 3 Sepuluh jenis tumbuhan dengan nilai preferensi tertinggi bagi badak jawa dan banteng

\begin{tabular}{lcclcc}
\hline \multicolumn{1}{c}{ Badak jawa } & & & \multicolumn{2}{c}{ Banteng } \\
\cline { 1 - 1 } \cline { 5 - 6 } Nama lokal & Preferensi & & Nama lokal & Preferensi \\
\hline Waru lot (Thespesia populnes) & 0,679 & & Oar (Flagellaria indica) & 0,307 \\
Kuku Heulang (Uncaria sp.) & 0,342 & & Jejerukan (Acronychia laurifolia) & 0,154 \\
Kopo (Eugenia subglauca) & 0,265 & & Paci-paci (Leucas lavandulifolia) & 0,138 \\
Kawao (Derris tyorsifolia) & 0,193 & & Pacing (Costus specistus) & 0,124 \\
Tokbrai (Blumeodendron tokbrai) & 0,170 & & Kibarela (Cayratia genicula) & 0,121 \\
Segel (Dillenia excelsa) & 0,123 & & Rotan Hejo (Heteroideus palleus blume) & 0,098 \\
& 0,117 & & Laja Goa (Alpinia sp.) & 0,094 \\
Haremeng (Cratoxylon racemosum) & 0,116 & & Talingkup (Claoxylon polot) & 0,094 \\
Kanyere Laut (Desmodium umbellatum) & 0,109 & & Rotan Seuti (Calamus ornatus Blume) & 0,089 \\
Ipis Kulit (Syzygium lineatum) & 0,096 & & Kipare (Breynia racemosa) & 0,086 \\
\hline
\end{tabular}

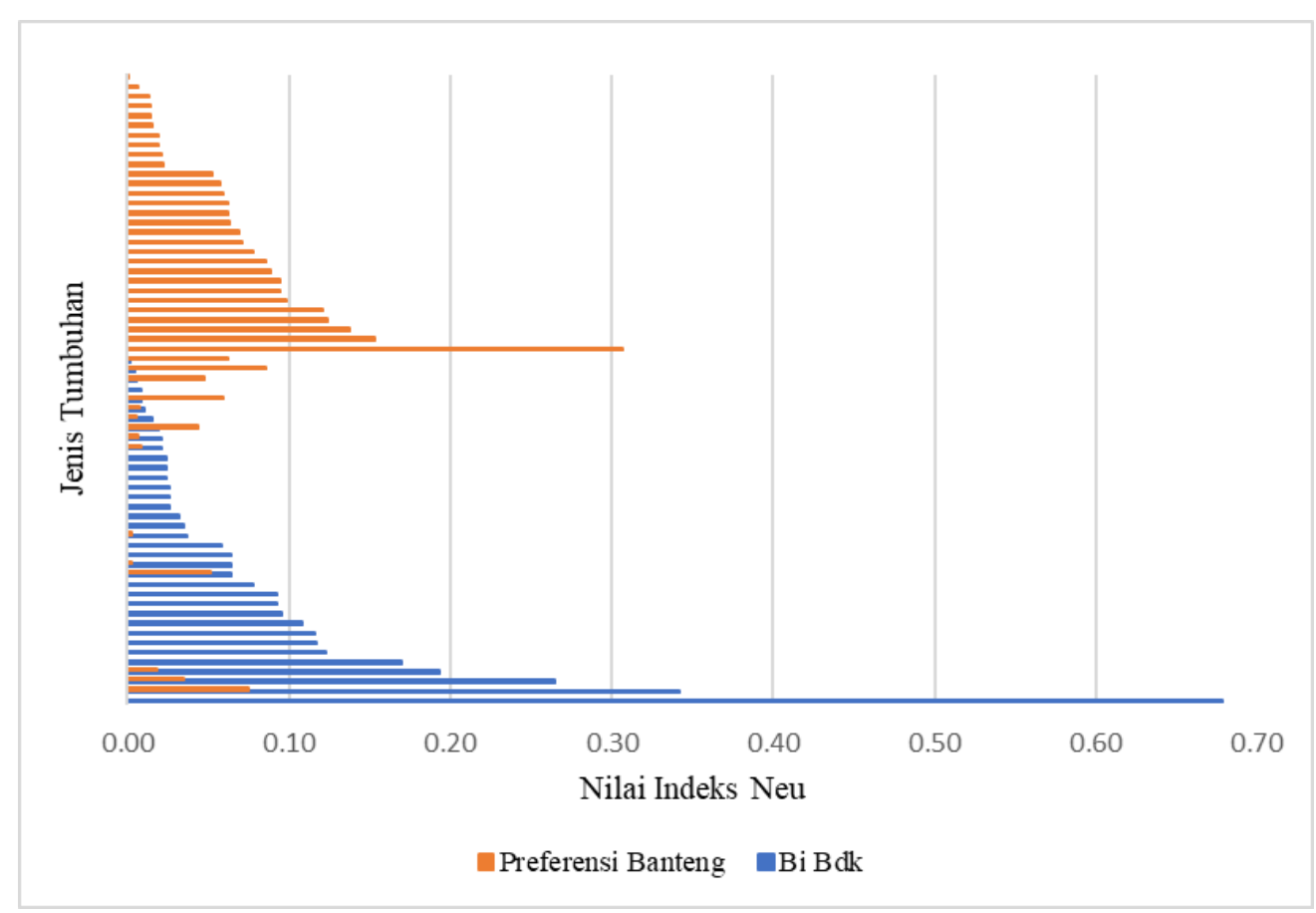

Gambar 3 Diagram perbandingan preferensi jenis pakan badak jawa dan banteng

Nilai yang sangat tinggi pada Gambar 3 menggambarkan ketersediaan jenis tersebut yang sedikit namun justru menjadi pilihan untuk dimakan. Distribusi nilai preferensi juga dapat dilihat pada tingkat famili tumbuhan dengan melakukan perhitungan rata-rata nilai preferensi dari jenis tumbuhan yang termasuk dalam famili tumbuhan yang sama. Terdapat 40 famili tumbuhan yang tercatat dimakan salah satu atau kedua spesies dengan 12 famili vegatasi yang hanya dimakan oleh badak saja, 14 famili tumbuhan hanya dimakan oleh banteng saja dan 14 famili tumbuhan yang tumpang tindih dimakan oleh kedua spesies. Famili Lecythidaceae adalah kelompok famili tumbuhan dengan nilai preferensi yang cukup mirip antara badak jawa dan banteng yaitu bernilai sekitar 0,05 .
Distribusi preferensi pakan badak jawa dan banteng pada tingkat famili juga menunjukkan pengelompokan yang memisahkan jenis yang disukai oleh badak jawa dari jenis yang disukai oleh banteng (Gambar 4). Famili tumbuhan yang tumpang tindih juga mempunyai perbandingan nilai yang cukup berbeda antara badak jawa dan banteng. jenis yang disukai oleh badak jawa cenderung tidak disukai oleh banteng. Badak jawa dan banteng mempunyai kecenderungan nilai preferensi yang rendah kecuali beberapa jenis tumbuhan yang kelimpahannya sangat rendah namun dimakan oleh kedua spesies pada plot tertentu. Hal tersebut menujukkan bahwa kemungkinan banteng mempunyai sifat yang cenderung generalis dalam pemilihan jenis pakan. 


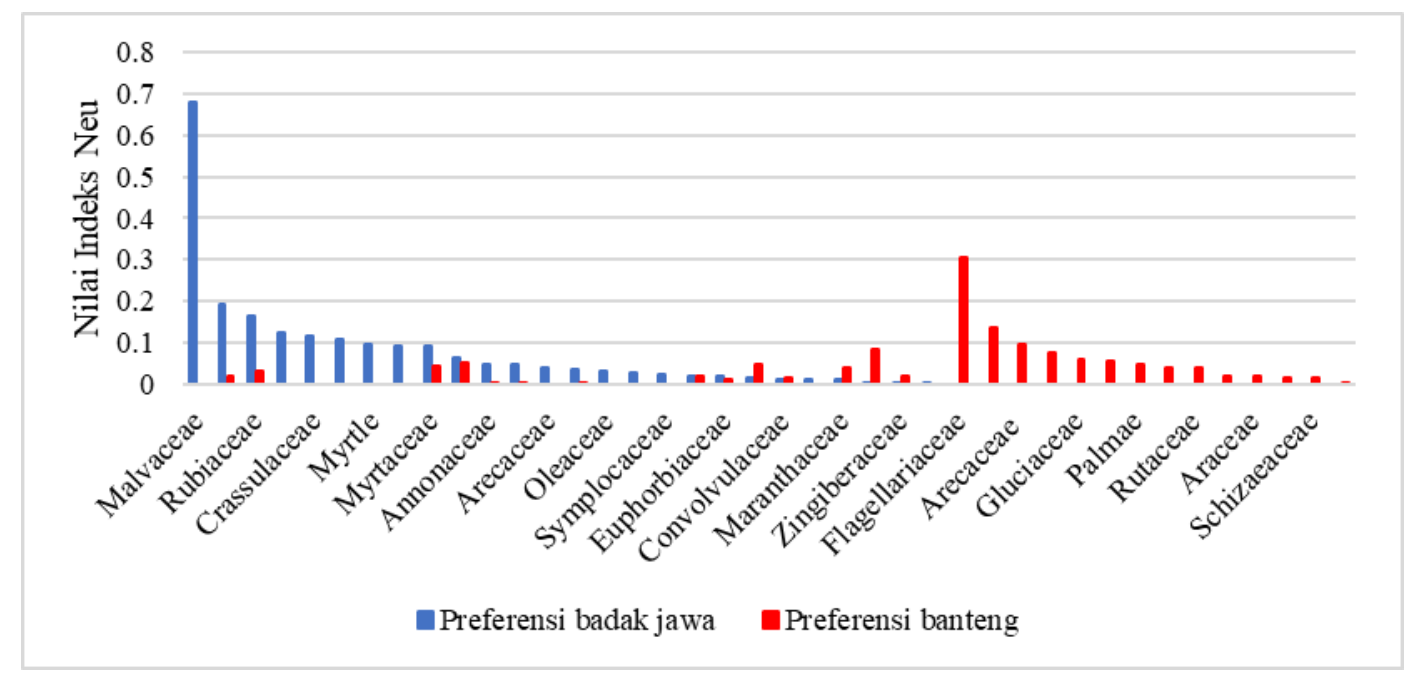

Gambar 4 Diagram preferensi pakan badak jawa dan banteng dalam tingkat famili

Hasil penelitian ini mengarah kepada kesimpulan yang cukup berbeda dari hasil penelitian-penelitian sebelumnya mengenai persaingan antara badak jawa dan banteng. Hasil analisa preferensi pakan dari kedua spesies mengindikasikan bahwa tumpang tindih jenis yang terjadi masih sangatlah sedikit dan bahkan terjadi pengelompokan tumbuhan pakan yang berbeda antara badak jawa dan banteng pada tingkat jenis maupun famili. Tumpang tindih jenis tumbuhan dengan nilai preferensi tinggi tidak terjadi antara kedua spesies sehingga sangatlah kecil kemungkinan terjadi perebutan pakan yang terbatas sehingga salah satu atau kedua spesies mengalami kerugian dan dapat dikategorikan sebagai persaingan (Birch 1957).

Setiap jenis satwaliar mempunyai karaktertistik dan kebutuhan yang berbeda-beda namun terkadang tidak bisa mengelak untuk hidup di habitat tertentu yang sama. Oleh karenanya karakteristik dan kebutuhan dari satwaliar tersebut akan menentukan strategi yang akan dipilih untuk menjamin keberlansungan hidupnya dalam pemenuhan kebutuhan pada suatu habitat yang dihuni oleh berbagai spesies. Strategi yang dipilih oleh setiap spesies akan menentukan peran mereka dalam relung ekologi (Elton 1927). Ketika suatu sumberdaya yang terbatas menjadi kebutuhan penting bagi beberapa jenis makhluk hidup maka makhluk hidup itu akan mencari cara untuk dapat menggunakan sumberdaya tersebut bersama-sama sampai kepada batas toleransi yang masih dapat mereka terima. Pilihan sumberdaya yang ada jika tidak mencukupi dan membuat salah satu atau beberapa spesies kalah dalam perebutan maka akan pergi untuk mencari sumberdaya yang sama di tempat lain, melakukan adaptasi terhadap sumberdaya yang masih melimpah atau punah (Gause 1934).

Kompetisi sendiri harus didefinisikan dengan lebih pasti karena tidak semua satwa dengan kebutuhan sumberdaya yang sama bisa dikategorikan dalam kompetisi selama spesies-spesies tersebut masih dapat berbagi. Menurut Birch (1957) seharusnya istilah kompetisi didefinisikan secara terbatas bahwa kompetisi muncul ketika beberapa orgnanisme menggunakan sumberdaya yang sama terbatas ataupun tidak terbatas namun dalam proses pemenuhan kebutuhan sumberdaya tersebut mengancam (mengusir) organisme lain yang mempunyai tujuan yang sama. Kesimpulan telah terjadi atau belum terjadi kompetisi sebenarnya tidak dapat disimpulkan hanya dengan mengidentifikasi tumpang tindih kebutuhan sumberdaya namun harus sampai kepada identifikasi bentuk kerugian yang ditimbulkan dari pola interaksi yang terjadi.

Penelitian ini hanya sedikit mengupas mengenai kemungkinan perebutan salah satu jenis sumberdaya yaitu pakan. Setiap makhluk hidup membutuhkan banyak aspek sumberdaya dan kondisi untuk dapat bertahan hidup (Begon et al. 2006). Sumberdaya adalah segala sesuatu yang dikonsumsi oleh makhluk hidup (Tilman 1982) dan kondisi adalah faktor abiotik lingkungan yang mempengaruhi berfungsi atau tidaknya suatu makhluk hidup (Begon et al. 2006). Bagi ikan, air dan salinitas merupakan kondisi yang memungkinkan atau tidak memungkinkannya untuk hidup namun bagi satwa teresterial kedua komponen tersebut adalah sumberdaya yang dikonsumsi agar tubuhnya bisa berfungsi dengan baik. Sumberdaya dan kondisi mempunyai jenis yang sangat banyak dan berbeda untuk setiap makhluk hidup dan penelitian ini hanya membahas salah satu sumberdaya saja. Oleh karena penelitian mengenai pola konsumsi sumberdaya dan kondisi lingkungan dari badak jawa dan banteng diperlukan untuk dapat melihat dengan lebih komprehensif bentuk dan pola interaksi antara kedua spesies. Dengan demikian perencanaan pengelolaan bagi kedua spesies juga dapat dirancang dengan lebih baik. 


\section{SIMPULAN}

Tidak ditemukan bukti telah terjadi kompetisi jenisjenis tumbuhan pakan antara badak jawa dan banteng. Terjadi pembagian relung pakan antara badak jawa dan banteng di Taman Nasional Ujung Kulon yang mengindikasikan bahwa kedua spesies dapat koeksis pada habitat tersebut.

\section{DAFTAR PUSTAKA}

Albrecht M, Gotelli NJ. 2001. Spatial and temporal niche partitioning in grassland ants. Oecologia. 126: 134-141.

Alikodra HS. 1983. Ekologi banteng (Bos javanicus, d'Alton 1823) di Taman Nasional Ujung Kulon [disertasi]. Bogor: Institut Pertanian Bogor.

Alikodra HS. 2002. Pengelolaan Satwaliar. Bogor: Yayasan Penerbit Fakultas Kehutanan Institut Pertanian Bogor.

Begon M, Townsend CR, Harper JL. 2006. Ecology: from Iindividuals to Ecosystems. Malden: Blackwell Pub.

Birch LC. 1957. The meanings of competition. The American Naturalist. 91:5-18. doi: $10.1086 / 281957$.

Elton CS. 1927. Animal Ecology. by Charles Elton: with an introduction by Julian S. Huxley. New York: MacMillan Co.

Gauze GF. 1934. The Struggle for Existence. Baltimore: The Williams \& Wilkins.

Gillison AN, Liswanti N, Rachman IA. 1996. Rapid Ecological Assessment, Kerinci Seblat National Park Buffer Zone [working paper]. Bogor: CIFOR.

[KLHK] Kementerian lingkungan Hidup dan Kehutanan. 2019. KLHK jelaskan kemataian badak jawa di TNUK [internet]. [diacu 2019 Desember 24]. Tersedia dari https://dataalam.menlhk.go.id/berita/2019/04/30/klh k-jelaskan-kematian-badak-jawa-di-tnuk

MacKenzie DI, Nichols JD, Royle JA, Pollock KH, Bailey LL, Hines JE. 2006. Occupancy Estimation and Modeling : Inferring Patterns and Dynamics of Species Occurrence. Burlington: Elsevier.

Mahmud R, Rahmaningsih M, Sunarto S, Firdaus A, Daryan, A Muhtarom, R Setiawan. 2016. Javan Rhino (Rhinoceros sondaicus), banteng (Bos javanicus) \& other mammals coexistence in Ujung Kulon National Park: Spatial and temporal overlap, 37-49. Research and Development Center of Environment Institute for Research and Community Service University of Lampung. 2016. Proceeding
International Wildlife Symposium 3. Bandar Lampung: Universitas Lampung.

Muntasib EKSH, Masyud B. 2000. Perubahan pola makan banteng (Bos javanicus) dan pengaruhnya terhadap badak jawa (Rhinoceros sondaicus) di Taman Nasional Ujung Kulon. Hayati. 7(3): 71-74.

Neu CW, Byers CR, Peek JM. 1974. Technique for analysis of utilization-availability data. Journal of Wildlife Management. 38: 541-545.

O'Hara RB. 2005. Species richness estimators: how many species can dance on the head of a pin? Journal of Animal Ecology. 74: 375-386

Pradhan NMB, Wegge P, Moe SR, Shrestha AK. 2008. Feeding ecology of two endangered sympatric megaherbivores: Asian elephant Elephas maximus and greater one-horned rhinoceros Rhinoceros unicornis in lowland Nepal. Wildlife Biology. 14: 147-154.

Richmond OMW, Hines JE, Beissinger SR. 2010. Two-species occupancy models: a new parameterization applied to co-occurrence of secretive rails. Ecological Applications. 20: 20362046.

Suhono S, Muntasib EKSH. 2001. Penggunaan sumberdaya air, pakan dan cover oleh badak jawa (Rhinoceros sondaicus, Desmarest 1822) dan banteng (Bos javanicus, dÁlton 1832) di Daerah Cikeusik dan Citadahan Taman Nasional Ujung Kulon. Media Konservasi. 7(2): 69-74.

Tilman D. 1982. Resource Competition and Community Structure. Monogr. Pop. Biol. 17. Princeton: Princeton University Press. .

Timmins RJ, Duckworth JW, Hedges S, Steinmetz R \& Pattanavibool A. 2008. Bos javanicus. The IUCN Red List of Threatened Species 2008: e.T2888A9490684.

http://dx.doi.org/10.2305/IUCN.UK.2008.RLTS.T2 888A9490684.en. 16 October 2019.

Van Strien NJ, Steinmetz R, Manullang B, Sectionov, Han KH, Isnan W, Rookmaaker K, Sumardja E, Khan MKM \& Ellis S. 2008. Rhinoceros sondaicus. The IUCN Red List of Threatened Species 2008: e.T19495A8925965. http://dx.doi.org/10.2305/IUCN.UK.2008.RLTS.T1 9495A8925965.en. 16 October 2019.

Wiens JA. 1992. The Ecology of Bird Communities. Cambridge: Cambridge University Press

[YMR] Yayasan Mitra Rhino. 2002. Studi Persaingan Ekologi badak jawa (Rhinoceros Sondaicus) dan banteng (Bos javancus) di Taman Nasional Ujung [laporan]. Bogor: YMR. 